\title{
Prevalence of Soil Transmitted Helminths in Some Birds Kept at Federal University Of Agriculture Abeokuta (FUNAAB) Zoo Park, Abeokuta, Nigeria
}

\section{1*BEKEH, JA; ${ }^{1}$ SAM-WOBO, SOH; ${ }^{2}$ ODIAKA, IE; ${ }^{2}$ ADEBISI-FAGBOHUNGBE, TA; ${ }^{2}$ GANIYU, OA; ${ }^{2}$ OLADIPUPO-ALADE, EO; ${ }^{2}$ HAASTRUP, NO; ${ }^{2}$ OYEDELE, MD}

\author{
${ }^{I}$ Federal University of Agriculture Abeokuta, PMB 2240, Abeokuta, Ogun State \\ ${ }^{2}$ Forestry Research Institute of Nigeria, PMB 5054, Jericho Hills, Ibadan Oyo State, Nigeria \\ *Corresponding Author Email: ifyx007@yahoo.com; ifyine78@gmail.com; Tel: +2348062774803
}

\begin{abstract}
Captive-held wild animals are those housed in zoological exhibits, rehabilitation centres, zoos, research stations, sanctuaries, aquaria, circuses, and plantations. However, parasitic diseases constitute one of the major problems causing mortality in these animals while in captivity. The effects range from sub-clinical to death; hence, the study was conducted to assess the gastrointestinal parasite profile of birds kept in Federal University of Agriculture, Abeokuta Zoo Park. Freshly voided faecal samples of Psittacus erithacus, Psittacula krameri, Balaerica pavonina, pavo cristatus, Chen caerulescens, Struthio camelus and Anas platyrhynchos were collected before routine cleaning. Samples were collected weekly for 8 weeks between 7am- 9am within the month of October and November, 2019. A total of 56 faecal samples from 7 birds were picked from the ground by utilizing a sterile scoop for each animal species to avoid cross contamination. Each sample was put in a new labelled sterile bottle with the name of each bird from which the faecal sample was collected. Samples were then transported to the laboratory for microscopic analysis which was done within 24 hours. Egg counting was done using the McMaster Egg Counting Technique. Identification of intestinal helminth ova was done by using the keys. Data obtained were analysed using SPSS version 20.0 and Microsoft excel. Prevalence was calculated while the weekly egg counts of intestinal helminthes were presented using descriptive statistics. The distribution of intestinal helminthes infections among the surveyed birds vary from (Psittacula krameri $100 \%$, pavo cristatus $100 \%$, Psittacus erithacus $66.67 \%$, Balaerica pavonina $66.67 \%$, Chen caerulescens $66.67 \%$, Struthio camelus $66.67 \%$, and Anas platyrhynchos $66.67 \%$ ). In conclusion, the prevalence of soil transmitted helminthes revealed that Ascaridiagalli and Strongyloides spp had the highest prevalence among the birds with $100 \%$ while Raillietina spp recorded the lowest prevalence with $28.6 \%$.
\end{abstract}

\section{DOI:https://dx.doi.org/10.4314/jasem.v25i6.2}

Copyright: Copyright $\odot$ (C21Bekehet al. This is an open access article distributed under the Creative Commons Attribution License (CCL), which permits unrestricted use, distribution, and reproduction in any medium, provided the original work is properly cited.

Dates: Received: 20 March 2021; Revised: 27 April 2021; Accepted: 07 May 2021

Keywords: Prevalence, soil transmitted diseases, Birds

Captive-held wild animals are those housed in zoological exhibits, rehabilitation centres, zoos, research stations, sanctuaries, aquaria, circuses, and plantations. These animals are kept for purposes like education, entertainment, relaxation, research, cultural, transportation, labour and preservation of endangered species (Egbetade et al., 2014). Zoological gardens exhibit wild animals for aesthetic, educational and conservation purposes. However, parasitic diseases constitute one of the major problems causing mortality in these animals while in captivity (Rao and Acharjyo, 1984; Varadharajan and Kandasamy, 2000). The effects range from subclinical to death.Birds are oviparous; they reproduce by laying eggs rather than giving birth to live young ones (Gill and Donsker, 2012). The eggs are adapted to survive in a terrestrial environment and have a porous shell made of calcium carbonate. They all have bills (beaks) which are toothless and swallow food without chewing. They have two stomach compartments (stomach glandular and stomach gizzard) (Sam-Wobo et al., 2017). Hutchinson (1987) reported that birds form a class of animal that includes other species worldwide.

These species were traditionally divided into thirty orders but a recent list group birds into 23 to 40 orders (Gill and Donsker, 2012; Clements, 2007).The word "Helminth" refers to a variety of worms that live in or on human and animal bodies. They are multicellular, eukaryotic and possess digestive, circulatory, nervous, excretory, and reproductive systems. The major groups of parasitic helminths include: platyhelminths (flatworms), acanthocephalans (thorny-headed worms) cestodes (tapeworms), trematodes (flukes) and nematodes (roundworms) (Boundless, 2016). The groups are characterized by the presence of attachment organs that define their parasitic living. These 
attachment organs include suckers, rostellum with hooks, oral and ventral suckers, lips, teeth, filariform extremities, and dentary plates. The numbers, shapes and location of these attachment organs vary among the groups and are sometimes taxonomic in function (Bethony et al., 2006). Infection with these parasites is generally termed helminthiasis. They are soiltransmitted, vector-borne or water based. Together they constitute important public health challenges facing humans, especially in the sub-Saharan Africa (Laughlin, 1998). Helminthiasis is a well-recognized health problem in ranging animals' especially subclinical nematode infection which limits the productivity of birds (Dimaner et al., 2000; Johannes et al., 2009). Bogitsh et al. (2005) reported that the study of captive animals' diseases is of veterinary importance, as gastrointestinal helminthes have been implicated in the cause of important diseases of human and animals. Gastrointestinal helminthes infection has been reported to associate with economic losses to zoo management worldwide which is revealed in chronic infection, weight loss, reduction in eggs and meat production (Bogitsh et al., 2005). The study of Blood and Radostitis (1989) shows that the variation in the prevalence of parasite intensity depends on the geographical locations, environment, immunological and nutritional status of the host, presence of intermediate host and the number of infective larva or eggs ingested by the animals. Considering the enormous evidence on the impact of helminthes on the profits and well- being of livestock and particularly birds (Ndarathi et al., 1989; Edosomwan and Ewarami, 2012), few studies exist in Nigeria on the investigation of helminth status of birds in zoological parks (Morenikeji and Otegbade, 2014;Egbetade et al., 2014;Adegbulu et al., 2015). Studies have shown that the number of infective larva stage presence in the soil is related to the number of helminths eggs passed by the host.

This largely determines the number of helminthes potentially capable of being established in a susceptible host (Pfukenyi and Mukaratirwa 2013). However, characteristics such as breed, age and the nutritional status of the host have a considerable influence on the parasitic helminths and their capacity to infect the host (Rivera et al., 1983). Therefore, investigating the types of intestinal helminthes among birds would further contribute to improving the health conditions of birds. This study will be conducted to determine the prevalence of gastrointestinal helminth infection found among birds in the FUNAAB zoo park, Abeokuta, Ogun State with the aim of improving the health status of the animals for productivity.

\section{MATERIALS AND METHODS}

Study Area: This research samples were collected from the Federal University of Agriculture, Abeokuta Zoological Park, which was established in 2008 but officially opened in 2010. The Zoo Park is located within Odeda Local Government Area of Ogun State in South-West, Nigeria within coordinates 7.22191 N, $3.444437 \mathrm{E}$ (figure 1). The climate in the study site is characterized by both dry and wet seasons and relatively high humidity (Morenikeji and Otegbade, 2014; Egbetade et al., 2014; Adegbulu et al., 2015; Sam-Wobo et al., 2017).There are varieties of animal species in the zoological park; and is divided into 6 sections for proper management. These sections include; Non-human primates, Carnivores, Ungulates, Rodents, Reptiles and birds. The birds housed in the park are classified in table 1 . Some animals are housed in un-cemented enclosures, while others are housed in cemented enclosures and cages, which are cleaned on a daily basis. Each species of the animals were kept separately in a large area which is structured in ways that mimic their natural environment and allows for free movement. The zoological park is demarcated and fenced to prevent movement by poachers and passers' by (Sam-Wobo et al., 2017).

Study Approval: A letter of introduction was obtained from the Department of Pure and Applied Zoology, Federal University of Agriculture, Abeokuta for permission to collect samples from the zoo birds. The letter was approved by the Director of Zoological garden, prior to the conduct of the study.

Pre-survey investigation: A pre-survey investigation was carried out in the zoological garden in order to document the number of captive bird species present in the garden (Table 1). The information on the age of the birds was not available as most of them were bought from local hunters.

Study Animals: The animals include Grey Parrot, Rose Ringed Parakeet, Crowned Crane, Peafowl, White Geese, Common Ostrich, and Mallard Duck.

Collection of stool samples: Early morning and freshly voided faecal samples of birds were collected before routine cleaning of all cages in the zoo. Samples were collected weekly for 8 weeks between 7am- 9am between the month of October and November, 2019. All samples were picked from the ground by utilizing a sterile scoop for each animal species to avoid cross contamination. Each sample was put in a new labelled sterile bottle with the name of each bird from which the faecal sample was collected. Samples were then 
transported to the laboratory for laboratory and microscopic analysis which was done within 24 hours.

Table 1: Classification of birds studied in FUNAAB Zoological Park.

\begin{tabular}{lllll}
\hline S/N & Common Name & Scientific Name & Family & Order \\
\hline $\mathbf{1}$ & Grey Parrot & Psittacus erithacus & Psittacidae & Psittaciformes \\
$\mathbf{2}$ & Rose Ringed Parakeet & Psittacula krameri & Psittaculidae & Psittaciformes \\
$\mathbf{3}$ & Crowned Crane & Balaerica pavonina & Gruidae & Gruiformes \\
$\mathbf{4}$ & Peafowl & Pavo cristatus & Phasianidae & Galliformes \\
$\mathbf{5}$ & White Geese & Chen caerulescens & Anatidae & Anseriformes \\
$\mathbf{6}$ & Common Ostrich & Struthio camelus & Struthionidae & Struthioniformes \\
$\mathbf{7}$ & Mallard Duck & Anas platyrhynchos & Anatidae & Anseriformes \\
\hline
\end{tabular}

Table 2: Distribution of intestinal helminth in avian species surveyed in FUNAAB zoological park

\begin{tabular}{|c|c|c|c|c|c|}
\hline \multirow[b]{2}{*}{$\mathbf{S} / \mathbf{N}$} & \multirow[b]{2}{*}{ Types of bird } & \multicolumn{4}{|c|}{ Type and Number of Parasites Ova observed } \\
\hline & & $\begin{array}{l}\text { Ascaridia } \\
\text { galli }\end{array}$ & $\begin{array}{l}\text { Strongyloides } \\
\text { spp }\end{array}$ & $\begin{array}{l}\text { Raillietina } \\
\text { spp }\end{array}$ & $\begin{array}{l}\text { Total Parasites } \\
\text { Observed }\end{array}$ \\
\hline 1 & Grey parrot & 2 & 1 & 0 & 3 \\
\hline 2 & Rose-ringed parakeet & 4 & 1 & 1 & 6 \\
\hline 3 & Crown crane & 2 & 2 & $\mathbf{0}$ & 4 \\
\hline 4 & Peafowl & 4 & 2 & 1 & 7 \\
\hline 5 & White Geese & 3 & 3 & $\mathbf{0}$ & 6 \\
\hline 6 & Ostrich & 4 & 3 & 0 & 7 \\
\hline 7 & Mallard Duck & 3 & 1 & $\mathbf{0}$ & 4 \\
\hline
\end{tabular}

Faecal analysis: Faeces were grossly examined for species-specific consistency, colour and presence of proglottids and adult worms. Direct microscopic examination (quick method) was done by placing a very small quantity of faecal dropping on a glass slide using a tooth pick and emulsify with a drop of water and place a cover slip to view on the microscope (Suwansaksri et al., 2002). Concentration techniques used was the simple salt $(\mathrm{NaCl})$ Floatation method as described by (Gillespie, 2006).T

Three gram of the sample was put into a beaker containing $42 \mathrm{ml}$ floatation fluid and stirred thoroughly. The resulting suspension was filtered into labelled test tubes arranged in a rack. The test tubes were gently filled with the suspension leaving a convex meniscus on the top of the tube and a cover slip was carefully placed on top of the test tube and allowed to stand for 20 minutes. The cover slip was carefully lifted and immediately placed on a clean microscope slide and examined under the microscope at 10x and 40x objectives for helminths egg.

Microscopic analysis: The already prepared glass slide was examined for helminths eggs under the microscope (10x and 40x) objective lens. Egg counting was done using the McMaster Egg Counting Technique as described by (MAFF, 1977).Identification of intestinal helminth ova was done by using the keys by (Soulsby, 1982) and (Sloss et al., 1994).
Statistical Analysis: Data obtained were subjected to statistical analyses using the Statistical Package for Social Sciences (SPSS) version 20.0. Prevalence values were calculated as number of positive samples/number of examined samples $\times 100$. Weekly egg count of intestinal helminthes was presented using descriptive statistics (line graphs for a weekly egg count of intestinal helminthes

\section{RESULTS AND DISCUSSION}

The distribution of intestinal helminth infections among the surveyed in which all the animals were found to be infected with eggs of two different parasite species (mixed infection) except for parakeet and peafowl which were infected with eggs of three different parasite species, although at different intensities as shown in Table 2.

The Prevalence Of Soil Transmitted Helminthes In The Research Animals: The prevalence of soil transmitted helminthes revealed that Ascaridiagalli and Strongyloides spp had the highest prevalence among the birds with $100 \%$ while Raillietina spp recorded the lowest prevalence with $28.6 \%$ while Capillaria spp was not present at all during the course of this study as shown in table 3 .

Correlation Coefficient Between The Size And Types Of Parasites Found In The Study Animals: As shown in table 4 Ascaridiagalli and Strongyloides spp are moderately correlated with each other and also with the size of the birds while Raillietina spp is moderately

BEKEH, JA; SAM-WOBO, SOH; ODIAKA, IE; ADEBISI-FAGBOHUNGBE, TA; GANIYU, OA; OLADIPUPOALADE, EO; HAASTRUP, NO; OYEDELE, MD 
correlated with to Ascaridiagalli and weakly correlated to Strongyloides spp and doesn't even correlate at all with the size of the animals.

Table 3: Prevalence of gastrointestinal parasitic infection in surveyed birds of FUNAAB Zoological garden

\begin{tabular}{llll}
\hline Infection & $\begin{array}{l}\text { Number of } \\
\text { birds } \\
\text { examined }\end{array}$ & $\begin{array}{l}\text { Number } \\
\text { of birds } \\
\text { infected }\end{array}$ & $\begin{array}{l}\text { Percentage } \\
\text { of infection } \\
(\%)\end{array}$ \\
\hline Ascaridiagalli & 7 & $7(7)$ & 100 \\
Capillariaspp & 7 & $0(7)$ & 0 \\
Strongyloides spp. & 7 & $7(7)$ & 100 \\
Raillietina spp. & 7 & $2(7)$ & 28.6 \\
\hline
\end{tabular}

Table 4: Correlation coefficient between the size and types of parasites found in the study animals

\begin{tabular}{|c|c|c|c|c|c|c|}
\hline & & $\begin{array}{l}\text { Ascaridia } \\
\text { galli }\end{array}$ & $\begin{array}{l}\text { Capillavia } \\
\text { spp }\end{array}$ & $\begin{array}{l}\text { Strongyloides } \\
\text { spp }\end{array}$ & $\begin{array}{l}\text { Raillietina } \\
s p p\end{array}$ & sizes \\
\hline \multirow{3}{*}{ Ascaridia galli } & Pearson Correlation & 1 & 2 & 0.293 & 0.477 & 0.461 \\
\hline & Sig. (2-tailed) & & & 0.524 & 0.279 & 0.298 \\
\hline & $\mathrm{N}$ & 7 & 7 & 7 & 7 & 7 \\
\hline \multirow{3}{*}{ Capillavia spp } & $\begin{array}{l}\text { Pearson Correlation } \\
\text { Sig. (2-tailed) }\end{array}$ & $=$ & $=$ & $=$ & $=$ & $=$ \\
\hline & $\mathrm{N}$ & 7 & 7 & 7 & 7 & 7 \\
\hline & Pearson Correlation & 0.293 & $=$ & 1 & 0.114 & 0.272 \\
\hline \multirow[t]{3}{*}{ Strongyloides sp } & Sig. (2-tailed) & 0.524 & & & 0.808 & 0.555 \\
\hline & $\mathrm{N}$ & 7 & 7 & 7 & 7 & 7 \\
\hline & Pearson Correlation & 0.477 & $=$ & 0.114 & 1 & -0.418 \\
\hline \multirow[t]{2}{*}{ Raillietina spp } & Sig. (2-tailed) & 0.279 & & 0.808 & & 0.350 \\
\hline & $\mathrm{N}$ & 7 & 7 & 7 & 7 & 7 \\
\hline \multirow{2}{*}{ Sizes } & $\begin{array}{l}\text { Pearson Correlation } \\
\text { Sig. (2-tailed) }\end{array}$ & $\begin{array}{l}0.461 \\
0.298\end{array}$ & $=$ & $\begin{array}{l}0.272 \\
0.555\end{array}$ & $\begin{array}{r}-0.418 \\
0.350\end{array}$ & 1 \\
\hline & $\mathrm{N}$ & 7 & 7 & 7 & 7 & 7 \\
\hline
\end{tabular}

${ }^{a}$ Cannot be computed because at least one of the variables is constant

Table 5: Sex and description of housing conditions of the birds surveyed

\begin{tabular}{|c|c|c|c|c|}
\hline $\mathrm{S} / \mathrm{N}$ & Species & Number & Sex & Housing Status \\
\hline 1 & Psittacus erithacus & 2 & Dimorphic & $\begin{array}{l}\text { Restricted in triangular cage built with } \\
\text { strong irons }\end{array}$ \\
\hline 2 & Psittacula krameri & 1 & Dimorphic & $\begin{array}{l}\text { Restricted in triangular cage built with } \\
\text { strong irons }\end{array}$ \\
\hline 3 & Balaerica pavionina & 2 & Dimorphic & $\begin{array}{l}\text { Restricted in triangular cage built with } \\
\text { strong irons with swimming puddles } \\
\text { included in the house }\end{array}$ \\
\hline 4 & Pavo cristatus & 2 & 1 male, 1 female & $\begin{array}{l}\text { Restricted in triangular cage built with } \\
\text { strong irons where the Balaerica } \\
\text { pavonina species are kept also }\end{array}$ \\
\hline 5 & Chen caerulescens & 4 & 3 males, 1 female & $\begin{array}{l}\text { Restricted in triangular cage built with } \\
\text { strong irons with swimming puddles } \\
\text { included in the house }\end{array}$ \\
\hline 6 & Struthio camelus & 2 & 1 male, 1 female & $\begin{array}{l}\text { Congtructed with triangular iron, iron } \\
\text { pipe, wooden stands, covered with } \\
\text { wire. Vegetation and large space } \\
\text { around the cage to mimic natural } \\
\text { habitat }\end{array}$ \\
\hline 7 & Anas platyrhynchos & 4 & $\begin{array}{l}2 \text { males }, 2 \\
\text { females }\end{array}$ & $\begin{array}{l}\text { Restricted in triangular cage built with } \\
\text { strong irons with swimming puddles } \\
\text { included in the house }\end{array}$ \\
\hline
\end{tabular}

Demography of birds in Funaab Zoo Park: Demography of Birds surveyed and the types of materials used in constructing their housing facilities is shown in table 5.An overall 7 (100\%) of 7 birds faecal samples were infected with gastro-intestinal parasites the prevalence recorded for most nematode identified in this study has also been reported by various authors it's in tandem withtheir previous studies (Morenikeji and Otegbade, 2014; Egbetade et al., 2014; Adegbulu et al., 2015; Sam-Wobo et al., 2017; Opara et al., 2010; Akinboye et al., 2010).

In the zoo birds, nematodes helminthes were more prevalent and this finding agrees with the reports of (Rossanigo and Gruner, 1995) that nematodes were responsible for most of the helminth diseases of veterinary importance, because they don't need 
intermediate hosts. The prevalence of gastrointestinal parasites in zoo birds can be explained by husbandry dependent factors such as housing and feeding, inconsistency in treatment program, or the existence of favourable climatic conditions (Magona and Musisi, 1999).At the zoo, the birds were housed in either cemented or uncemented cages with daily cleaning. Most of the birds were fed with grains. Furthermore, all the parasites found in this study were transmitted faecal-orally through contaminated soil, food, and water. As a result, these may play a key role as sources of parasite infection to birds under captivity conditions. The most frequently encountered gastrointestinal parasite, Ascaridiagalli are large roundworms occurring in the small intestine. In heavy infections, it may cause partial or total obstruction of the duodenum or the jejunum and infection is usually asymptomatic, but birds with heavy parasite burden may show clinical signs of loss of appetite, drooping wings, ruffled feathers, loss of weight, decreased egg production, anaemia, diarrhoea and mortality (Anders and Jorgen, 1998). None of the infected birds with Ascaridiagalli in this study showed any of the clinical signs which suggest mild to moderate infection at sub clinical level. Helminthiasis, most especially infection with soil transmitted helminthes (STH), which ova accumulate in the environment, particularly in open soil enclosures, which cannot be easily disinfected constitute a major and big problem to wild animals in captivity (Elena, 2011). The occurrence of Ascaridiagalli in Crown crane, white geese and Mallard duck could be attributed to their environment which allows for free movement around the facilities and it is also constructed with a swimming place which can get easily contaminated with eggs of helminthes (Anders and Jorgen, 1998) while in ostrich could be attributed to the accessibility to viable faecal samples.Generally, the poor environmental hygiene observed in the zoological garden might contribute to the development and transmission of intestinal helminth infections, responsible for feeding captive animals havebeen implicated in continued transmission of intestinal helminth infections (Adekunle and Olayide, 2008). Contaminated cooking utensils and infected zookeepers responsible for feeding the animals might contaminate animal feeds. The introduction of foods to animals with contaminated hands and dirty finger nails can also be implicated in the transmission of intestinal helminths.

Conclusion: Gastrointestinal parasitic infection is a burden in the zoological park, so in regards to the biology of the helminths parasites in the transmission of disease condition, continuous regular deworming of the animals i.e. the use of antihelminthic drugs, quarantine services for newly acquired animals and improved hygiene practices should be incorporated into the zoological garden animal health management practices to reduce the transmission rates of the helminths parasites. Also the personal hygiene attitudes and practices of zookeepers should be emphasized, policy barring visitors from feeding the animals in the zoo should be enforced so as to prevent visitors from infecting the animals and thus improve the health of the captive animals.

\section{REFRENCES}

Adegbulu, Y.T., Mogaji, H.O., Oluwole, A.S., Alabi, O.M., Adeniran, AA; Ekpo, UF (2015). A Preliminary Survey of Gastrointestinal Parasites of Animals in Federal University of Agriculture Abeokuta Zoological Park, Ogun State, Nigeria. J. Bio. Agric. Healthcare5 (11):195-202

Anders, P. and Jorgen, W.H. (1998) Epidemiology, Diagnosis and Control of Poultry parasites. Food and Agriculture Organization of the United Nations.

Boundless. (2016). Classification and Identification of Helminths. Boundless Microbiology. https://www.boundless.com/microbiology/textbo oks/boundless-microbiology textbook/microbialevolution-phylogeny-and-diversity8/helminths116/classification-and identificationof-helminths-604-406.

Clements, J.C/ (2007). Checklist of birds of the world.6th edition New York: Cornell University.

Dimaner, S.O., Hoglund, J., Sporndy, E. and Waller, P.J. (2000). The impact of internal parasites on the productivity of birds. Vet. Parasite. 90:271-284

Edosomwan, E.U; Ewarami, T.J. (2012). Helminth parasites of birds at Ikpoba hill abattoir Benincity, Edo State, Nigeria. Biol. Environ. Sci. J. Trop. 9(1):179-183.

Gill, F. and Donsker (2012) D. IOC World Bird Names (v.3.1). http://www.worldbirdnames.org.

Johannes, C., John, H., George, V.S., Pierre, D Inzef, V. (2009). Gastrointestinal nematode in 864 impact on production, diagnosis and control. Vet. Parasitology. 164:70-79.

Laughlin, L.W. (1998). Helminthiasis among Primary School Children in Lere Local Government Area Kaduna State, Nigeria. Nig. J. Para. 21: 109-116. 
Callum, H. and Dobson, A. (1995). Detecting disease and parasite threats to endangered species and ecosystems. Trend in Ecol. Evol. 10(5):190-194.

Meyer, K. (1940). Psittacosis. The Auk, 57(3): 330332.

Morenikeji, O/A. and Otegbade, A. C. (2014). Gastrointestinal parasites of birds in zoological gardens in South-West Nigeria. Trop. Biomed. 31(1):54-62.

Pfukenyi, D.M and Mukaratirwa, S. (2013). A review of the epidemiology and control of gastrointestinal nematode infections. Onderstepoort. J. Vet. Res. 80(1)

Rao, A.T. and Acharjyo, L.N. (1984). Diagnosis and classification of common diseases of captive animals at Nandankana Zoo in Orissa (India). Indian J. Animal Sci. 2: 147-157.
Rivera, B., Parra, D., Garcia, O; Aycardi, E. (1983). Gastro-intestinal parasites in birds. Trop. Anim. Health Product. 15:107-114.

Sam-Wobo, S.O., Innocent, N.P., Oyatogun, I., Surakat, O.A. and Mogaji, H. (2017).Status of helminths in birds kept in Zoological Park, Abeokuta, Nigeria.J. Entomol. Zoo. Stud. 5 (6): 390-394.

Varadharajan, A; Kanadasamy, A. (2000). A Survey of Gastrointestinal Parasites of Wild Animals in Captivity in the V.O.C. Park and Mini Zoo, Coimbatore. Zoo's Print Journal. 15(5): 257-258. 